\title{
GERMINAÇÃO DE AQUÊNIOS DE ARNICA (Lychnophora pinaster Mart.) ARMAZENADOS EM DIFERENTES CONDIÇÕES ${ }^{1}$
}

\author{
Seed germination of arnica (Lychnophora pinaster Mart) \\ stored at different conditions
}

\author{
Paulo Régis Bandeira de Melo², João Almir Oliveira³, José Eduardo Brasil Pereira Pinto, \\ Evaristo Mauro de Castro ${ }^{3}$, Antônio Rodrigues Vieira ${ }^{4}$, José Renato Emiliorelli Evangelista ${ }^{5}$
}

\section{RESUMO}

A antecipação da coleta pode contribuir para redução da rápida deterioração das sementes no campo, preservando, assim, sua qualidade fisiológica. No caso da arnica (Lychnophora pinaster Mart.), a formação dos aquênios ocorre de maneira desuniforme na planta, sendo dristibuída ao longo do período de frutificação. Assim, em se tratando de uma espécie medicinal não domesticada, ameaçada de extinção, e tendo seu potencial genético ainda pouco estudado, urge a necessidade de monitoramento do comportamento dos aquênios no armazenamento, visando garantir sua reprodução e conseqüente preservação. Esse trabalho foi conduzido com a finalidade de se verificar o desempenho germinativo de aquênios de arnica coletados em dois estádios de maturação e armazenados em diferentes condições. Os aquênios utilizados foram provenientes do município de Itumirim, MG, tendo a coleta sido realizada em dezembro de 2003, em função das características morfológicas dos capítulos, constituindo, assim, dois estádios de maturação. Após a coleta, os aquênios foram submetidos à secagem, pré-limpeza e separados com auxílio de um soprador vertical. Os aquênios foram acondicionados em dois tipos de embalagens (papel ou plástico) e armazenados em diferentes ambientes (câmara fria a $10^{\circ} \mathrm{C} / 50 \% \mathrm{UR}$ ou ambiente de laboratório), por um período de 6 meses. $\mathrm{O}$ teste de germinação foi conduzido em $\mathrm{BOD}$ ajustada à temperatura alternada $20-30^{\circ} \mathrm{C}$ e fotoperíodo de 12 horas. O substrato utilizado foi o papel mata-borrão e os aquênios foram dispostos em caixas plásticas tipo gerbox. Foram utilizadas 4 repetições de 100 aquênios para cada tratamento. A análise sanitária foi efetuada pelo método "Blotter test" com 4 repetições de 50 aquênios por tratamento. As avaliações da umidade, da qualidade fisiológica e sanitária foram realizadas aos 0, 2, 4 e 6 meses. Pelos resultados, verificou-se que não houve diferença entre as quatro condições de armazenamento e, nestas condições, pode-se armazenar aquênios de arnica por um período de seis meses. Houve um aumento da germinação ao longo do período de armazenamento.

Termos para indexação: Semente, planta medicinal, maturação.

\begin{abstract}
Early seed collection may contribute to decrease its deterioration rate preserving physiological quality. Seed formation in arnica (Lychnophora pinaster Mart.), takes place throughout the fructification period. As arnica plant is of medicinal importance and is under threaten there is a need of monitoring seed quality during storage to guarantee reproduction and perpetuation of the species. This work was performed with the objective of verifying germination performance of arnica seeds collected at two maturation stages and stored at different conditions. The seeds used in this study were collected in December 2003 at Itumirim, State of Minas GeraisBrazil at two maturation stage. After collection, the seeds were dried, cleaned and separated with a vertical blower. The seeds were placed in two types of packing (paper and plastic) and stored under different atmospheres (cold chamber $10^{\circ} \mathrm{C} / 50 \% \mathrm{RH}$ and room temperature), during 6 months. The germination test was performed in incubator (BOD) at alternate temperature $\left(20-30^{\circ} \mathrm{C}\right)$ and photoperiod of 12 hours. The substrate used was paper towel and the seeds were placed in gerbox. Four replication of 100 seeds for each treatment were used. The sanitary quality of the seed was performed by "Blotter test" with 4 replications of 50 seeds for each treatment. Moisture content, sanitary quality and physiological quality were evaluated during $0,2,4$ and 6 months. There was not significant differences among the four storage conditions and, under these conditions, arnica seeds can be stored by a period of six months. There was an increase in the germination along the storage period.
\end{abstract}

Index terms: Seed, medicinal plant, maturation.

(Recebido para publicação em 22 de março de 2005 e aprovado em 20 de setembro de 2005)

\section{INTRODUÇÃO}

A arnica (Lychnophora pinaster Mart) é uma espécie que apresenta propriedades medicinais, pertence à família Asteraceae e possui hábito de crescimento arbustivo. Sua ocorrência é restrita à campos rupestres, que constitui-se de afloramento de rochas, entre 800 a $2000 \mathrm{~m}$ de altitude, sendo considerada endêmica. Entretanto, a arnica encontra a sua perpetuação ameaçada nos dias atuais, pois o constante extrativismo associado a queimadas constantes tem levado a espécie a enquadrar-se na categoria de plantas vulneráveis (SBB, 1992).

\footnotetext{
${ }^{1}$ Parte da dissertação apresentada à Universidade Federal de Lavras/UFLA pelo primeiro autor, para a obtenção do grau de mestre em Agronomia. 'Engenheiro Agrônomo graduado pela Universidade Federal de Lavras/UFLA - Cx. P. 3037 - 37.200-000 - Lavras, MG.

${ }^{3}$ Professores da Universidade Federal de Lavras/UFLA - Cx. P. 3037 - 37.200-000 - Lavras, MG - jalmir@ufla.br

${ }^{4}$ Pesquisador da EPAMIG/CTSM - Campus da Universidade Federal de Lavras/UFLA - Cx. P. 176 - Lavras, MG.

${ }^{5}$ Aluno de graduação de Agronomia da Universidade Federal de Lavras/UFLA - Cx. P. 3037 - 37.200-000 - Lavras, MG.
} 
Conforme Semir (1991), aquênios de arnica encontram-se em sub-capítulos de capítulos, apresentando papus internos e externos como estrutura de dispersão. Silva (1994) estudou a arnica quanto aos aspectos da fenologia e reprodução sexuada, por considerar importante e urgente a obtenção de informações científicas sobre o seu comportamento em hábitat natural e seus aspectos reprodutivos. Essa autora separou a frutificação em três fases distintas; após antese e simultâneamente a senescência das flores, aquênios com papus interno presente e aquênios com papus interno ausente, já em dispersão. Seu trabalho permitiu concluir que a arnica apresenta comportamento fenológico sazonal em relação aos seus aspectos vegetativos, reprodutivos e dispersão dos frutos, em função das variações climáticas. Além disso, maior porcentagem de germinação e índice de velocidade de germinação dos aquênios são possíveis em condições de laboratório, quando se utilizam caixas acrílicas tipo "gerbox", em substrato entre papel mata-borrão e temperaturas alternadas $20-30^{\circ} \mathrm{C}$.

Segundo Carvalho \& Nakagawa (2000), em algumas espécies, o atraso em relação ao momento ideal para a colheita pode resultar em perdas quantitativas e qualitativas em função da degrana das sementes maduras e, se antecipada, pode ter sua realização dificultada pela presença de grande quantidade de imaturas. Esse problema acentua-se nas plantas medicinais, por serem espécies pouco ou recém-domesticadas, nas quais a desuniformidade de florescimento e de maturação, somada à degrana e à deiscência, constituem em relevantes mecanismos de dispersão das sementes e conseqüente perpetuação das espécies. Neste contexto, a antecipação da colheita tornase relevante para preservar uma boa qualidade fisiológica, evitando-se uma rápida deterioração das sementes no campo e, posteriormente, no armazenamento.

A deterioração de sementes é um processo degenerativo contínuo, que se inicia no estádio após maturidade fisiológica e continua até a perda da viabilidade e a morte da semente. Dependendo das condições ambientais e de manejo, pode haver, a seguir, a redução da qualidade fisiológica das sementes, pela intensificação do fenômeno da deterioração (MARCOS FILHO, 2005).

$\mathrm{O}$ armazenamento inicia-se no campo, em decorrência das variáveis ambientais, podendo variar em função da espécie, qualidade inicial das sementes e condições às quais foram submetidas. Após a semente ter atingido seu ponto máximo de qualidade fisiológica, fatores adversos devem ser eliminados para que essa qualidade seja preservada. Desde que a semente tenha sido colhida, seca, beneficiada, eliminando-se fatores desfavoráveis que reduzem a qualidade fisiológica durante essas operações, a preservação da qualidade fica na dependência das condições de armazenamento da semente (MARCOS FILHO, 2005; POPINIGIS, 1985).

De acordo com Carvalho \& Nakagawa (2000), vários autores atribuem à umidade relativa influência direta na respiração das sementes, sendo esse o fator mais importante que afeta o potencial de armazenamento. Dessa forma, para várias espécies, a conservação será melhor com níveis baixos de umidade. Entretanto, existem espécies cuja viabilidade e vigor são perdidos com a desidratação, interferindo sobremaneira no armazenamento em condições secas. Bewley \& Black (1994) classificam o primeiro grupo como ortodoxas e recalcitrante as sementes cujo comportamento enquadra-se no segundo grupo.

Durante o armazenamento, a temperatura e a umidade relativa do ar, que envolvem as sementes, constituem dois fatores extremamente importantes para que se mantenha o poder germinativo das mesmas. Vários são os fatores relacionados com a manutenção da viabilidade e do vigor durante o armazenamento: umidade inicial das sementes, umidade relativa do ar, temperatura de armazenamento, microrganismos, insetos, tipo de embalagem e duração do período de armazenamento (MARCOS FILHO, 2005; POPINIGIS, 1985).

$\mathrm{O}$ aumento da temperatura do ambiente de armazenamento provoca aumento da taxa respiratória da semente, de fungos e de insetos que a acompanham (MCDONALD, 1999). Duas categorias de fungos são associadas às sementes: fungos de campo e fungos de armazenamento. Os fungos de campo, segundo Bewley \& Black (1994), têm sua incidência reduzida durante o armazenamento; por outro lado, fungos de armazenamento, dependendo das condições, desenvolvem-se e tendem a elevar sua ocorrência afetando negativamente a qualidade das sementes armazenadas.

Outro fator relacionado à conservação da qualidade fisiológica da semente, sob determinadas condições de umidade relativa do ar e de temperatura, é a embalagem utilizada durante o período de armazenamento. De acordo com Desai et al. (1997), os materiais usados para embalagem de sementes são: tecido de juta e de algodão, papel, celofane, alumínio, polietileno, vidro e metal, que podem ser empregados isoladamente ou em composição (laminados). Por sua vez, baseado no tipo de material utilizado, Popinigis (1985) classificou as embalagens empregadas no acondicionamento da semente em: permeáveis, semipermeáveis e impermeáveis à umidade. 
Portanto, com este trabalho, visou-se verificar o desempenho germinativo de aquênios de arnica, coletados em dois estádios de maturação e armazenados em diferentes condições.

\section{MATERIAL E MÉTODOS}

O presente trabalho foi conduzido no Laboratórios de Análise de Sementes (LAS), de Patologia de Sementes (LPS) e de Análise de Sementes Florestais da Universidade Federal de Lavras, no período de 2003 a 2004.

A coleta dos aquênios foi realizada no município de Itumirim, MG, no mês de dezembro de 2003, sendo efetuada em plantas adultas com tamanho superior a um metro de altura. Os capítulos foram cortados com tesoura, em diversas posições nas plantas, e acondicionados em sacos plásticos com capacidade para 20 litros.

Foram realizadas quatro coletas em dias distintos, sendo as duas primeiras referentes ao estádio cujo papus interno, estrutura de dispersão, apresentava-se aderido aos aquênios presentes nos capítulos (Estádio 1). As coletas subseqüentes referiram-se ao estádio em que não havia mais a presença de papus interno, sendo que os aquênios já encontravam em dispersão (Estádio 2).

Após separação manual de aquênios dos capítulos, de uma pequena amostra, foi determinada a umidade no momento da coleta.

A umidade dos aquênios foi determinada pelo método de estufa a $105^{\circ} \mathrm{C}$, durante 24 horas, conforme as prescrições das Regras para Análise de Sementes (BRASIL, 1992). Por ocasião da montagem do teste de germinação, foram retiradas duas amostras de um grama de aquênios para cada tratamento, tendo os resultados expressos em porcentagem.

Após a coleta, os capítulos foram submetidos à secagem em estufa de circulação de ar forçado, com temperatura variando de $25^{\circ} \mathrm{C}$ a $30^{\circ} \mathrm{C}$ por 72 horas, até a umidade aproximada de $10 \%$. Após a secagem, os capítulos foram debulhados e, juntamente com os aquênios eventualmente desprendidos, foram submetidos ao beneficiamento.

Os capítulos foram debulhados manualmente e posteriormente passaram por um processo de pré-limpeza utilizando-se um protótipo da máquina de ar e peneira para retirada das impurezas. Foi efetuado repasse para retirada do excesso do material indesejável. O peso do material obtido foi de $1.036,78 \mathrm{~g}$ para o estádio $1 \mathrm{e} 707,40 \mathrm{~g}$ para o estádio 2. Logo em seguida, utilizando um soprador vertical modelo South Dakota, marca De Leo, foi realizado o beneficiamento dos aquênios utilizando-se a abertura 3,75 com repasse, no tempo de 2' e 40", tendo o mecanismo de ventilação desacionado automaticamente após esse período. O peso final de aquênios apurados foi de $134,32 \mathrm{~g}$ para o estádio 1, correspondendo a $13 \%$, e $98,18 \mathrm{~g}$ para o estádio 2, ou seja, 13,9\%.

Foi utilizada a técnica de raios $\mathrm{X}$ para se verificar a porcentagem de aquênios efetivamente cheios nos lotes após o beneficiamento. A potência e o tempo adotados, que permitiram melhor visualização e distinção dos aquênios, foram obtidos em pré-testes. Os aquênios foram dispostos sobre fita adesiva transparente de dupla face, aderida a uma placa de acrílico transparente, com dimensões 24 x $18 \mathrm{~cm}$ e espessura de $2 \mathrm{~mm}$. Após montagem, a placa com os aquênios foi sobreposta ao filme radiográfico Kodak, Min-R 2000, tamanho 18 x 24 cm e submetida à radiação de $30 \mathrm{Kv}$, por 45 segundos, em equipamento de raio-X Faxitron HP, modelo 43855A X. Os filmes radiográficos foram revelados e analisados visualmente sobre transiluminador. Foram utilizadas 4 repetições de 50 aquênios.

Os aquênios foram acondicionados em dois tipos de embalagem: sacos de papel kraft bifoliado e embalagens plásticas cilíndricas (pote escuro com volume de $30 \mathrm{~mL}$, utilizado para acondicionamento de filme fotográfico) e armazenados em condição ambiente de laboratório e câmara fria $\left(10^{\circ} \mathrm{C}\right.$ e UR $\left.50 \%\right)$. Constituiram-se, assim, quatro condições de armazenamento.

Para cada tratamento (estádios de maturação, condições e períodos de armazenamento) os recipientes continham $5 \mathrm{~g}$ de aquênios. Os períodos de armazenamento foram: $0,2,4$ e 6 meses.

Os aquênios foram semeados sobre duas folhas de papel mata-borrão, previamente umedecidas com água destilada com uma quantidade equivalente a 2,5 vezes o peso do substrato seco, acondicionados em caixas acrílicas do tipo "gerbox" e mantidas em BOD, à temperatura alternada de $20-30^{\circ} \mathrm{C}$ e iluminação de 12 horas. Foram utilizadas quatro repetições de 100 aquênios para cada tratamento. Foi adotado o critério de protrusão radicular para o cálculo do índice de velocidade de germinação (IVG), utilizando-se a fórmula proposta por Maguire (1962), sendo as avaliações realizadas em dias alternados. Para o teste de germinação, as avaliações foram realizadas aos $0,2,4$ e 6 meses, e adotou-se a porcentagem de plântulas normais, sendo as mesmas computadas e eliminadas periodicamente até 60 dias após a semeadura.

A análise de sanidade dos aquênios foi efetuada pelo método de papel de filtro ("Blotter test"), conforme descrito por Machado (1988) sem, contudo, utilizar pré- 
tratamentos para inibir a germinação. Foram utilizadas quatro repetições de 50 aquênios para cada tratamento. Os aquênios foram mantidos em câmara de incubação por um período de 7 dias, sob regime alternado de luz e escuro por 12 horas, a uma temperatura de $20^{\circ} \mathrm{C}$. Decorrido esse período, foi realizado o exame dos aquênios sob microscópio estereoscópico, sendo determinado o percentual e a identificação dos fungos ocorrentes.

O delineamento experimental utilizado foi inteiramente casualizado em esquema fatorial 4 x 2 x 4 (4 condições de armazenamento x 2 estádios x 4 épocas). Os dados obtidos no teste de germinação foram transformados em $\sqrt{x+0,5}$, conforme sugerido por
Banzatto \& Kronka (1995), submetidos à análise de variância e analisados pelo programa estatístico SISVAR. Foi utilizada regressão para estádios e épocas de armazenamento. Para o teste de sanidade e grau de umidade não foi realizada análise de variância.

\section{RESULTADOS E DISCUSSÃO}

O grau de umidade apresentado pelos aquênios, independente das embalagens e locais de armazenamento, para ambos os estádios, não sofreu grandes oscilações durante o período, permanecendo com um teor de água abaixo de $13 \%$, conforme ilustrado nas Figuras 1 e 2 .

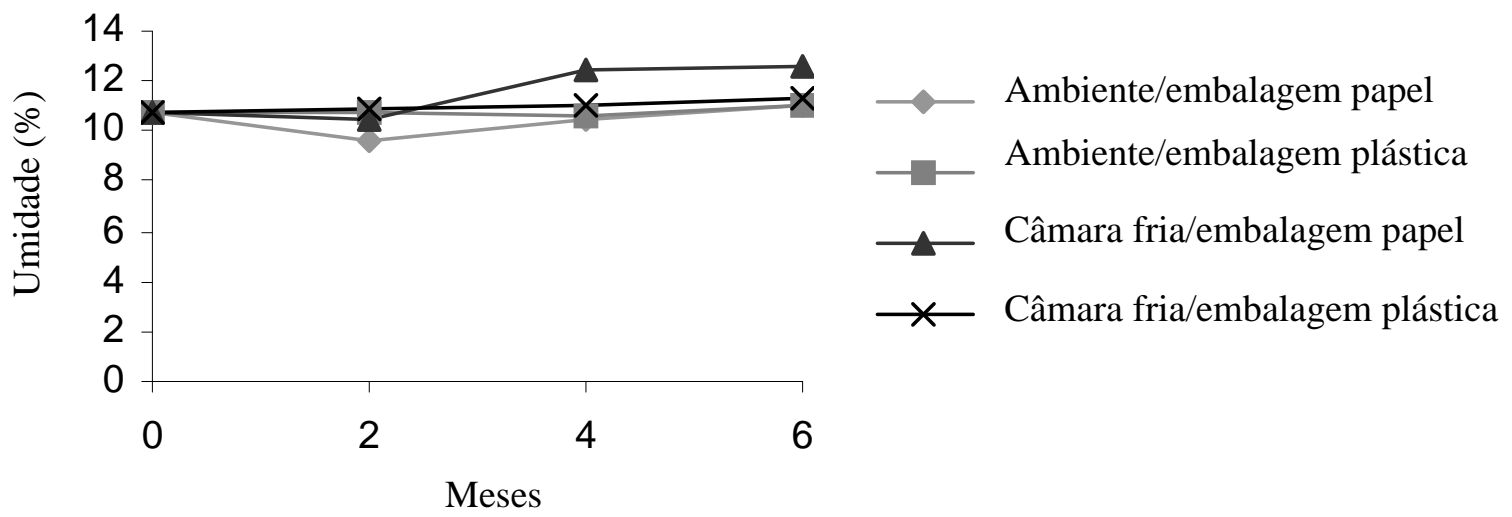

FIGURA 1 - Teor de água de aquênios de arnica coletados no estádio 1 de maturação, acondicionados em embalagens de saco de papel e embalagens plásticas e armazenados por um período de seis meses em ambiente de laboratório e em câmara fria. UFLA, Lavras, MG, 2005.

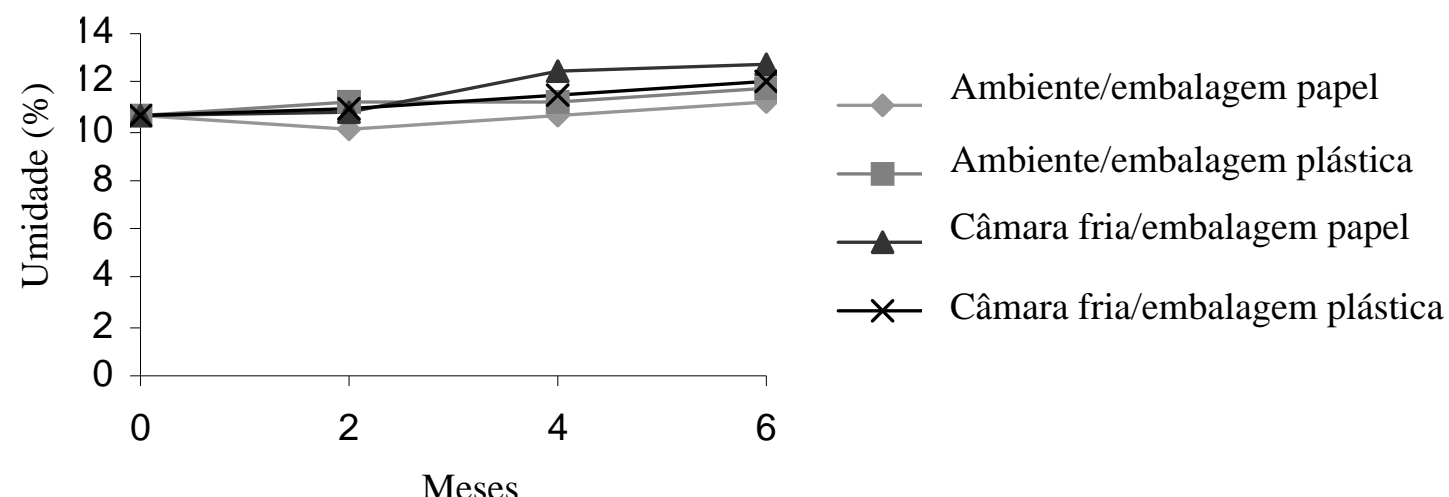

FIGURA 2 - Teor de água de aquênios de arnica coletados no estádio 2 de maturação, acondicionados em embalagens de saco de papel e embalagens plásticas e armazenados por um período de seis meses em ambiente de laboratório e em câmara fria. UFLA, Lavras, MG, 2005.

Ciênc. agrotec., Lavras, v. 31, n. 1, p. 75-82, jan./fev., 2007 
Pelos resultados da análise estatística houve interação significativa entre época de armazenamento e estádio de maturação, tanto para a germinação quanto para o índice de velocidade de germinação (IVG). Nas variáveis analisadas, não foi constatada diferença em relação às condições de armazenamento testadas.

Pelos resultados de regressão referentes aos dados obtidos pelo teste de germinação apresentado na Figura 3, observa-se que houve um decréscimo no percentual de germinação dos aquênios do estádio 2 até aos 2,8 meses de armazenamento, seguido de um acréscimo até aos seis meses quando encerrou-se o experimento. Esse comportamento pode ser explicado pela redução da qualidade fisiológica inicial de alguns aquênios, em função da desuniformidade de maturação e eventual processo de deterioração no armazenamento, decorrente do maior período que os aquênios do estádio 2 ficaram no campo expostos às condições ambientais variáveis, com posterior superação de dormência dos aquênios que se encontravam dormentes. É relevante ressaltar que a maturação dos aquênios ocorre de maneira desuniforme na planta o que, provavelmente, contribuiu para os resultados de deterioração de alguns e superação de outros aquênios com diferentes intensidades de dormência. Carvalho \& Nakagawa (2000) comentam que, na fase em que ocorre uma rápida desidratação, fase final da maturação, chuvas intensas podem promover um rápido processo de deterioração das sementes já maduras no campo.

Em relação ao estádio 1, aquênios menos maduros, observa-se que ocorreu aumento linear da germinação ao longo dos meses. Possivelmente, houve, nesse caso, uma remoção ou redução de dormência dos aquênios no período de armazenamento.

Ainda em relação à germinação, a avaliação dos aquênios cheios, considerados potencialmente viáveis, demonstrado em radiografia obtida previamente à destinação dos aquênios para as respectivas embalagens e condições de armazenamento, foi correspondente a $38,5 \%$ para o estádio 1 e $42 \%$ para o estádio 2. Esses dados, juntamente com a dormência apresentada pelos aquênios de arnica, auxiliam na interpretação da baixa germinação ocorrida.

Com relação aos resultados do índice de velocidade de germinação (IVG) apresentados na Figura 4, observa-se que também houve um crescimento linear do IVG ao longo do armazenamento para os aquênios do estádio 1. Para os aquênios do estádio 2, nota-se também um comportamento semelhante do IVG com a germinação, ou seja houve uma redução do índice até aos 2,8 meses de armazenamento $(0,197)$, seguido de um aumento, sendo que aos seis meses de armazenamento este índice foi de 0,306.

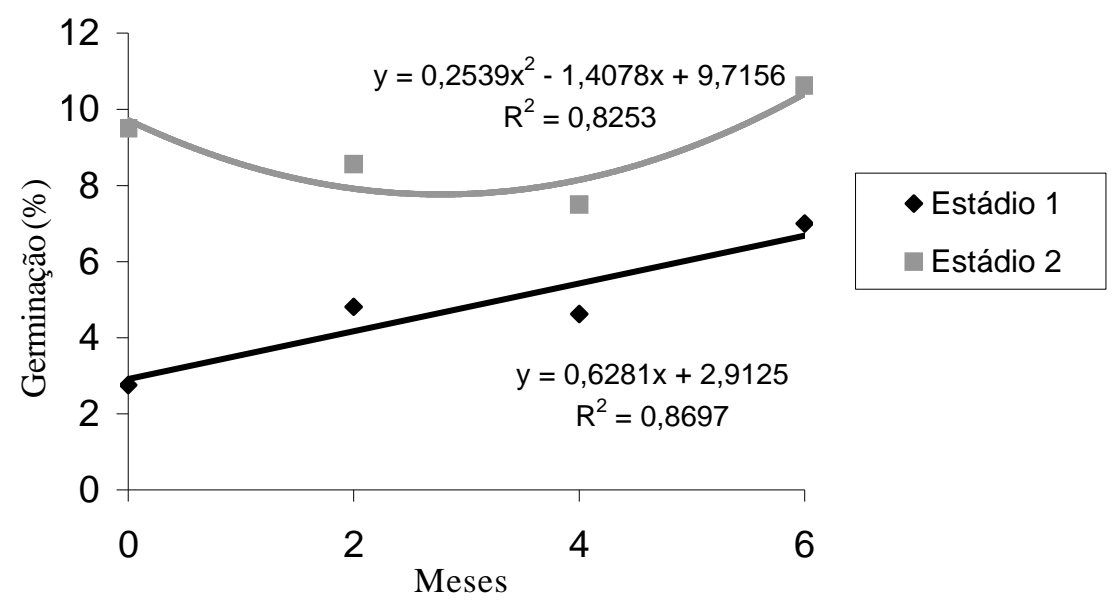

FIGURA 3 - Porcentagem de germinação de aquênios de arnica, em dois estádios de maturação, armazenados no período de seis meses e submetidos ao teste de germinação. UFLA, Lavras, MG, 2005. 


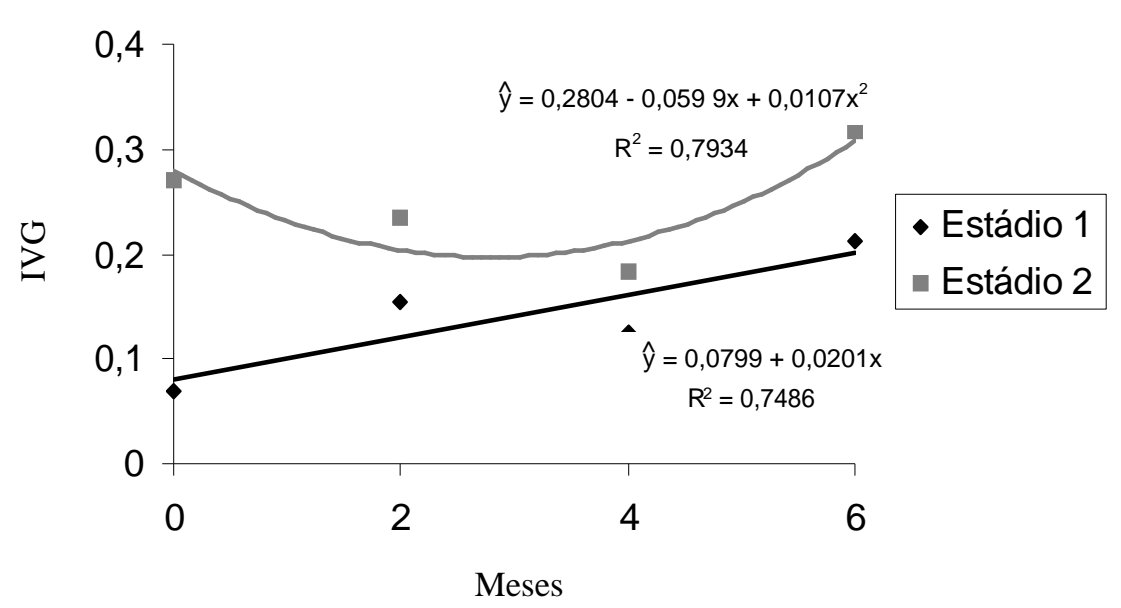

FIGURA 4 - Índice de velocidade de germinação (IVG) de aquênios de arnica, em dois estádios de maturação, armazenados por seis meses. UFLA, Lavras, MG, 2005.

A distinção entre os estádios de maturação foi observada para todas as épocas avaliadas, exceto no quarto mês. Neste ponto, houve uma tendência à aproximação do vigor dos dois estádios, pois os aquênios no estádio 1 encontravam-se num processo de superação da dormência mas, sobretudo em função do decréscimo acentuado da qualidade fisiológica dos aquênios no estádio 2 , cujo vigor só viria a aumentar com a quebra de dormência ocorrida no armazenamento, refletida após 2,8 meses de armazenamento.

$\mathrm{O}$ armazenamento pode variar em função da espécie, qualidade inicial das sementes e condições de armazenamento às quais foram submetidas. Em relação às condições de armazenamento, não houve diferença entre as médias para as variáveis germinação e índice de velocidade de germinação (IVG). Dessa forma, nota-se que as condições de armazenamento não interferiram na variação da germinação ocorrida ao longo do período de armazenamento.

É importante ressaltar que a umidade de coleta do estádio 2, aquênios mais maduros já em dispersão, encontrava-se em torno de $14 \%$. Nesta faixa de umidade, sementes consideradas ortodoxas encontram-se quiescentes e prontas para a dispersão, podendo apresentarem-se dormentes, dependendo da espécie (BRYANT, 1989). Contudo, em pré testes realizados, observou-se que alguns aquênios colocados em condições de germinação, logo após a coleta do estádio 1, com aproximadamente $30 \%$ de umidade e sem terem passado pelo processo de secagem, assim como o estádio 2 , também germinaram ao longo do período de 9 meses.
Pelos resultados do teste de sanidade (Tabela 1), observa-se que, nas condições de ambiente em laboratório, para ambas as embalagens, houve um decréscimo na incidência do fungo Alternaria alternata com o transcorrer do armazenamento. Em se tratando de um fungo saprófita, a sua constante presença nos aquênios em câmara fria, tanto em embalagens de papel quanto em plástico, não alterou os resultados de germinação. Em relação aos fungos característicos de armazenamento, Penicillium sp. e Aspergillus sp., observa-se que a incidência manteve-se constante ao longo do período de armazenamento, pois, de acordo com Bewley \& Black (1994), dependendo das condições, esses normalmente tendem a aumentar sua incidência no armazenamento. Esse controle eficiente pode ter sido proporcionado durante o armazenamento pela umidade abaixo de $13 \%$ (POPINIGIS, 1985), pois os aquênios de arnica não foram submetidos ao tratamento químico. Assim, a baixa qualidade fisiológica dos aquênios, refletida na germinação, sobretudo do estádio 2, que passou mais tempo exposto às variáveis ambientais no campo, pode ser atribuída às condições ambientais após a maturação dos aquênios.

Por outro lado, em função da germinação e grau de umidade apresentados pelos aquênios, por ocasião da coleta e no período de seis meses de armazenamento, nas embalagens e condições testadas, pode-se inferir que os dados tenderam a refletir o comportamento característico de sementes ortodoxas, que são sementes cuja viabilidade pode ser mantida por um período longo quando armazenadas com baixos teores de água (BEWLEY \& BLACK, 1994). 
CONCLUSÕES

O desempenho germinativo de aquênios de arnica não é afetado pelas condições de armazenamento no período de seis meses, independentemente do recipiente (papel ou plástico) ou do local de armazenamento (câmara fria a $10^{\circ} \mathrm{C} / 50 \%$ UR ou ambiente de laboratório).

O armazenamento promove incremento do percentual de germinação ao longo do período de seis meses, principalmente dos aquênios com papus interno presente por ocasião da coleta.

\section{REFERÊNCIAS BIBLIOGRÁFICAS}

BANZATTO, D. A.; KRONKA, S. N. Experimentação agrícola. 3. ed. Jaboticabal: FUNEP, 1995. 247 p.

BEWLEY, J. D.; BLACK, M. Seeds: physiology of develepment and germination. New York: Plenum, 1994.444 p.

BRASIL. Ministério da Agricultura e Reforma Agrária. Regras para análise de sementes. Brasília, DF: Secretaria Nacional de Defesa Ambiental, 1992. 365 p.

BRYANT, J. A. Fisiologia da Semente. São Paulo: EPU, 1989.86p.

CARVALHO, N. M.; NACAGAWA, J. Sementes: ciência, tecnologia e produção. Jaboticabal: FUNEP, 2000. 588 p.

DESAI, B. B.; KOTECHA, P. M.; SALUNKHE, D. K. Seeds handbook: biology, production, processing and storage. New York: M. Dekker, 1997.627 p.

MACHADO, J. C. Patologia de sementes: fundamentos e aplicações. Lavras: ESAL/FAEPE, 1988. 107 p.

McDONALD, M. B. Seed deterioration: physiology, repair and assessment. Seed Science and Technology, Zurich, v. 27, n. 1, p. 177-237, 1999.

MAGUIRRE, J. D. Speed of germination aid in selection and evaluation for seedling and vigour. Crop Science, Madison, v. 2, n. 2, p. 176-177, Mar./Apr. 1962.

MARCOS FILHO, J. Fisiologia de sementes de plantas cultivadas. Piracicaba: FEALQ, 2005. 495 p.

POPINIGIS, F. Fisiologia da semente. 2. ed. Brasília, DF: AGIPLAN, 1985. 289 p. 
SEMIR, J. Revisão taxonômica de Lychnophora Mart. pinaster Mart.) Asteraceae. 1994. 45 f. Dissertação (Vernoniaceae: Compositae). 1991.515 f. Tese (Doutorado (Mestrado) - Universidade Federal de Lavras, em Biologia Vegetal) - Universidade Estadual de Campinas, Lavras, 1994.

Campinas, 1991.

SILVA, S. M. P. da. Aspectos da fenologia e da

SOCIEDADE BOTÂNICA DO BRASIL. Centuria reprodução sexuada da arnica (Lychnophora

Plantarum Brasiliensium exstintionis minitata. Brasília, DF, 1992. 167 p. 